\title{
Knowledge, Attitude, and Awareness Related to COVID-19 Pandemic Among the Public, Saudi Arabia: A Cross-Sectional Descriptive Study
}

\author{
Alya Hassan Alhajjaj ${ }^{1^{*}}$ (D), Huda Hassan Aldarweesh ${ }^{1 * *}$ (D), Zainab Abdullah Alghawi ${ }^{1}$ (D) \\ ${ }^{1}$ Qatif Central hospital, Saudi Arabia \\ * Corresponding author: Alya Hassan Alhajjaj E-mail: alhajjajal@yahoo.com ORCID: 0000-0003-0055-3003 \\ ** Corresponding author: Huda Hassan Aldarweesh E-mail: huda.hassan17@gmail.com ORCID: 0000-0003-0887-6499 \\ Received: 19 May 2020 Accepted: 29 June 2020
}

\begin{abstract}
Background: COVID-19 infection has spread to many countries including Saudi Arabia. This study was designed to assess the knowledge, attitude and awareness among the public in Saudi Arabia about COVID-19 pandemic.

Materials and Methods: It was a cross-sectional online Arabic survey. It was conducted on $23^{\text {rd }}$ March 2020. It included all adult residents in Saudi Arabia.

Results: A total of 2069 questionnaires were returned completed. Most of the participants were females (78.2\%) and from the Eastern province (92.9\%). The median age was 35.69 years. The majority of the participants had sufficient knowledge (score $\geq 6$ ) with statistical significance in relation to age, gender, marital status, occupation and educational level. Most of them (75.90\%) got their knowledge about COVID-19 from Social media. The majority of the participants supported the government regulations and the protective measures taken for COVID-19 prevention. Most of them reported frequent handwashing and maintaining social distancing.

Conclusion: Although our study was conducted at the beginning of COVID-19 pandemic in Saudi Arabia, it showed that our participants had good knowledge level that was reflected on their positive attitude, awareness, and their precautionary measures. Because our participants were mainly from the Eastern province, further studies are needed to investigate other provinces in Saudi Arabia.
\end{abstract}

Keywords: knowledge, attitude, Saudi, COVID-19, public

\section{INTRODUCTION}

The rapid spread of a novel coronavirus (SARS-CoV2) from Wuhan city, China, has become an international health concern [1].
Since its emergence in late December 2019, the coronavirus diseases 2019 (COVID-19) has spread to many countries. As of May 10, 2020, there were 3,986,119 confirmed cases of COVID-19 and 278,814 deaths [2]. In Saudi Arabia, on March 2, 2020, the first confirmed case of COVID-19 was reported in Qatif Area located in the Eastern Province Region [3]. As of

@ 2020 by the authors; licensee EJMETS by Bastas, UK. This article is an open access article distributed under the terms and conditions of the Creative Commons Attribution License (http://creativecommons.org/licenses/by/4.0/). 
May 10, 2020, there were 39,048 confirmed cases of COVID19 in Saudi Arabia with 246 overall virus-related deaths [4].

The increase in number of confirmed cases and the absence of any preventive or therapeutic intervention, created an emphasis on the need to overcome the spread of COVID-19 through isolation of infected people at their homes, medical institutions, or hotels. Furthermore, cities and countries had been placed under lockdown and quarantine status to reduce human-to-human contact; starting with Wuhan city on January 23, 2020 [5]. Qatif Area was the first city in the Middle East to be placed under lockdown on March 8, 2020 [6].

Based on the recommendation made by the Centers for Disease Control and Prevention (CDC), and the National Institutes of Health (NIH); in regard to limiting the social contacts to prevent the disease spread, the Saudi Government closed schools and held off religious gatherings on March 9, 2020 [7]. In addition, on March 16, 2020, the Saudi Government decided to suspend attendance at workplaces in all government institutions and private sectors; except for certain occupations, mainly in the sectors of health, security, and military [8].

Although there are several published studies that explored the public knowledge, awareness, and practice (KAP) related to Middle East Respiratory Syndrome (MERS) $[9,10]$, there are only limited peer-reviewed similar studies during COVID-19 pandemic, despite the larger quarantine sizes and widespread global lockdowns on large geographical and urban areas. Zhong et al conducted a similar study in China to investigate the knowledge, attitude, feelings related to COVID-19 [11]. An online survey was conducted among all US adults to test the hypothesis that COVID-19 knowledge affects the practice and behavior related to COVID-19 preventive measures [12]. Wolf et al conducted a similar study in the Unites States but it was only for adults with chronic illnesses [13]. Abdelhafiz et al conducted a similar study among Egyptians and it was the first published peerreviewed study in the Middle East [14]. There are similar studies that direct special populations such nurses [15].

In spite of scarcity of peer-reviewed KAP publications, there are many preprints and non-peer reviewed papers that have been published among special population (such as university students) and public during COVID-19 pandemic $[16,17]$.

This descriptive cross-sectional online survey was started on March 23, 2020; approximately three weeks after the diagnosis of the COVID-19 index case in Qatif City. The aim of this survey is to examine the knowledge, awareness, and attitude related to COVID-19 pandemic among the public within the different regions of Saudi Arabia.

\section{METHODS}

\section{Study Design and Participants}

This descriptive cross-sectional online survey was conducted in accordance to the international guidelines of Strengthening the Reporting for Observational Studies in Epidemiology; STROBE, 2007. It was conducted during the Period between $23^{\text {rd }}$ and $30^{\text {th }}$ of March 2020. The inclusion criteria included all residents (Saudi and non-Saudi) in Saudi Arabia, both male and female, and aged above14 years. Participants below the age of 14 years were excluded.

\section{Validations of the Questionnaire}

After literature review for similar studies [9-11], our online questionnaire was created. To assess its validity and reliability, the survey questions were reviewed by two epidemiologists. According to their suggestions, some of the knowledge questions were modified to more relevant questions. Before sending this questionnaire to the public, thirty participants (who were excluded from the study later) were asked to fill the survey. Data were used to assess reliability and internal consistency of the questionnaire using cronbach's alpha.

\section{Data Collection}

Our validated questionnaire was distributed using Google forms with a shared link with the public through social media (WhatsApp and Twitter). The survey included closedended and multiple response questions. It was divided into four parts to address sociodemographic data, knowledge, attitude, and awareness related to COVID-19 pandemic among the participants. The first part included sociodemographic data such as age, gender, marital status, nationality, work sector and educational level. The second part, composed of eight questions, assessed the knowledge related to COVID-19 and included incubation period, clinical features, and the therapeutic interventions. The third part, composed of four questions, assessed the attitude of the participants toward the government regulations and the protective measures; including lockdowns imposed by the government on certain affected cities. The last part, composed of four questions, assessed the practice of the participants related to the prevention of the spread of COVID-19.

Scoring system was used to assess the level of knowledge: zero was given for each incorrect answer (no response) and 
Table 1. Sociodemographic characteristics of the participants and the score of knowledge

\begin{tabular}{|c|c|c|c|c|c|}
\hline \multirow{2}{*}{\multicolumn{2}{|c|}{ Variables }} & \multirow{3}{*}{$\begin{array}{c}\begin{array}{c}\text { Frequency (\%) } \\
\text { (Total: 2069) }\end{array} \\
616(29.80 \%)\end{array}$} & \multicolumn{2}{|c|}{ Score of knowledge (Total: 2069) } & \multirow{2}{*}{ P-value } \\
\hline & & & \multirow{2}{*}{\begin{tabular}{|c|}
0 to 5 (Total: 455$)$ \\
$202(32.8 \%)$
\end{tabular}} & \multirow{2}{*}{$\begin{array}{c}6 \text { to } 8 \text { (Total: 1614) } \\
414(67.2 \%)\end{array}$} & \\
\hline \multirow{4}{*}{ Age } & $15-29$ & & & & \multirow{4}{*}{$0.001^{*}$} \\
\hline & $30-44$ & $1014(49.00 \%)$ & $190(18.74 \%)$ & $824(81.26 \%)$ & \\
\hline & $45-59$ & $381(18.40 \%)$ & $54(14.18 \%)$ & $327(85.82 \%)$ & \\
\hline & 60 or above & $58(02.80 \%)$ & $9(15.51 \%)$ & 49 (84.48\%) & \\
\hline \multirow{2}{*}{ Gender } & Male & $452(\%)$ & $133(29.43 \%)$ & $319(70.57 \%)$ & \multirow{2}{*}{$0.00^{*}$} \\
\hline & Female & $1617(78.20 \%)$ & $322(19.92 \%)$ & $1295(80.08 \%)$ & \\
\hline \multirow{2}{*}{ Marital Status } & Married & $1475(71.30 \%)$ & $264(17.90 \%)$ & $1211(82.10 \%)$ & \multirow{2}{*}{$0.00^{*}$} \\
\hline & Non-married & $594(28.70 \%)$ & $191(32.16 \%)$ & $403(67.84 \%)$ & \\
\hline \multirow{2}{*}{ Nationality } & Saudi & $2044(98.80 \%)$ & $450(22.02 \%)$ & $1594(77.98 \%)$ & \multirow{2}{*}{0.776} \\
\hline & Non-Saudi & $25(01.20 \%)$ & $5(20.00 \%)$ & $20(80.00 \%)$ & \\
\hline \multirow{5}{*}{ Current Residency } & Eastern province & $1923(92.90 \%)$ & $420(21.84 \%)$ & $1503(78.16 \%)$ & \multirow{5}{*}{0.512} \\
\hline & Central region & $62(03.00 \%)$ & 13 (20.97\%) & 49 (79.03\%) & \\
\hline & Southern province & $50(02.40 \%)$ & $17(34.00 \%)$ & $33(66.00 \%)$ & \\
\hline & Western province & $7(00.30 \%)$ & $0(00.00 \%)$ & $7(100 \%)$ & \\
\hline & Northern province & $27(01.30 \%)$ & $5(18.52 \%)$ & $22(81.48 \%)$ & \\
\hline \multirow{8}{*}{ Job } & Medical field * & 397 (19.20\%) & $49(12.34 \%)$ & $348(87.66 \%)$ & \multirow{8}{*}{$0.00^{*}$} \\
\hline & Educational field * & $236(11.40 \%)$ & $32(13.56 \%)$ & 204 (86.44\%) & \\
\hline & Engineering field & $78(03.80 \%)$ & $15(19.23 \%)$ & $63(80.77 \%)$ & \\
\hline & Military field & $10(00.50 \%)$ & $4(40.00 \%)$ & $6(60.00 \%)$ & \\
\hline & Administrative field & $188(09.10 \%)$ & $39(20.75 \%)$ & $149(79.25 \%)$ & \\
\hline & Nonemployed & $616(29.80 \%)$ & $137(22.24 \%)$ & $479(77.76 \%)$ & \\
\hline & Student & $305(14.70 \%)$ & $110(36.07 \%)$ & 195 (65.93\%) & \\
\hline & Other & $239(11.60 \%)$ & $69(28.87 \%)$ & $170(71.13 \%)$ & \\
\hline \multirow{5}{*}{ Educational level } & Primary school & 31 (01.50\%) & $10(32.26 \%)$ & 21 (67.74\%) & \multirow{5}{*}{$0.00^{*}$} \\
\hline & Intermediate school & $61(02.90 \%)$ & $21(34.43 \%)$ & $40(65.57 \%)$ & \\
\hline & Secondary school & $527(25.50 \%)$ & $158(29.98 \%)$ & 369 (70.02\%) & \\
\hline & University & $1331(64.30 \%)$ & 255 (19.52\%) & $1076(80.84 \%)$ & \\
\hline & High education & $119(05.80 \%)$ & 69 (28.87\%) & $108(90.76 \%)$ & \\
\hline \multirow{2}{*}{$\begin{array}{l}\text { Personal or family history } \\
\text { of COVID-19 infection }\end{array}$} & Yes & $38(01.80 \%)$ & $6(15.79 \%)$ & 32 (84.21\%) & 0.82 \\
\hline & No & 2031 (98.20\%) & 449 (22.11\%) & $1582(77.89 \%)$ & (\%) \\
\hline
\end{tabular}

one point for each correct answer (yes response). The participants were grouped into two categories according to their level of knowledge: insufficient $(<6$ points) and sufficient ( $\geq 6$ points).

\section{Sampling}

The required sample size reached into 462 participants (including 20\% dropout rate). Sample size calculator was used, with the following criteria; $95 \%$ confidence interval, \pm 5 margin of error, $50 \%$ response distribution and an estimated population size of 34,218,169 (based on the most recent Saudi Arabia census that was conducted on 2019) [18].

\section{Statistical Analysis}

Data were coded, validated and analyzed using SPSS, version 21. A descriptive analysis was conducted and data were represented as percentage and frequency. Chi-square and the Analysis of Variance (ANOVA) tests were applied to find the association between different variables. The probability value ( $p$-value) of less than 0.05 was considered statistically significant.

\section{Ethic Consideration}

All participants were ensured full confidentiality. Although, participants aged above 14 years are considered adults in Saudi Arabia, we stated in our survey that for participants aged less than 18 years, a guardian's consent was mandatory. The study was approved by the Institutional Research Ethic Committee in Qatif Central Hospital, Saudi Arabia (QCH-SREC0194/2020).

\section{RESULTS}

\section{Sociodemographic Characteristics}

A total of 2,069 participants returned a completed questionnaire. Table 1 shows sociodemographic 
Table 2. Knowledge of the participants about COVID-19

\begin{tabular}{|c|c|c|}
\hline Question & Answer & $\begin{array}{l}\text { Frequency } \\
\text { (Total: 2069) }\end{array}$ \\
\hline \multirow{3}{*}{$\begin{array}{l}\text { The most common symptoms of COVID-19 } \\
\text { are fever, generalized weakness and dry } \\
\text { cough }\end{array}$} & Correct & $1986(96.00 \%)$ \\
\hline & Incorrect & $45(02.20 \%)$ \\
\hline & Neutral & $38(01.80 \%)$ \\
\hline \multirow{3}{*}{$\begin{array}{l}\text { Symptoms are usually mild in healthy } \\
\text { individuals but more severe in elderly } \\
\text { people and/or who have medical problems }\end{array}$} & Correct & $1570(75.90 \%)$ \\
\hline & Incorrect & $256(12.40 \%)$ \\
\hline & Neutral & $243(11.70 \%)$ \\
\hline \multirow{3}{*}{$\begin{array}{l}\text { The virus that cause COVID-19 is mainly } \\
\text { transmitted through contact with } \\
\text { respiratory droplet }\end{array}$} & Correct & $1838(88.80 \%)$ \\
\hline & Incorrect & $151(07.30 \%)$ \\
\hline & Neutral & $90 \%)$ \\
\hline \multirow{3}{*}{$\begin{array}{l}\text { The virus can be survived on the surfaces } \\
\text { for a few hours or up to several days }\end{array}$} & Correct & $1744(84.30 \%)$ \\
\hline & Incorrect & $208(10.10 \%)$ \\
\hline & Neutral & $117(05.70 \%)$ \\
\hline \multirow{3}{*}{$\begin{array}{l}\text { The symptoms of the disease appear after } \\
\text { two to fourteen days }\end{array}$} & Correct & $1903(92.00 \%)$ \\
\hline & Incorrect & $90(04.30 \%)$ \\
\hline & Neutral & $76(03.70 \%)$ \\
\hline \multirow{3}{*}{$\begin{array}{l}\text { Antimalarial treatment can be used to treat } \\
\text { the virus }\end{array}$} & Correct & $1152(55.70 \%)$ \\
\hline & Incorrect & $227(11.00 \%)$ \\
\hline & Neutral & $690(33.30 \%)$ \\
\hline \multirow{3}{*}{ We can not treat the virus with antibiotics } & Correct & $1196(57.80 \%)$ \\
\hline & Incorrect & $247(11.90 \%)$ \\
\hline & Neutral & $626(30.30 \%)$ \\
\hline \multirow{3}{*}{$\begin{array}{c}\text { Till now no vaccine available against the } \\
\text { virus }\end{array}$} & Correct & $1847(89.30 \%)$ \\
\hline & Incorrect & $48(02.30 \%)$ \\
\hline & Neutral & $174(08.40 \%)$ \\
\hline
\end{tabular}

characteristics. The majority of the participants were females (78.2\%), Saudis (98.8\%), and residents of the Eastern Province (92.9\%). Most of the participants (98.2\%) had no personal or family history of COVID-19. Almost $50 \%$ of the participants were in the age group 30-44 years with a median of 35.69 years.

\section{COVID-19 Knowledge and Source of Information}

Table 2 demonstrates the questions related to COVID-19 knowledge among the participants. The majority of the
Table 3. Attitude of the participants regarding COVID-19

\begin{tabular}{|c|c|c|}
\hline \multicolumn{2}{|l|}{ What is your opinion regarding } & Frequency \\
\hline \multirow{3}{*}{ Closing school and prevention of gathering } & Agree & $2017(97.5 \%)$ \\
\hline & Disagree & $9(0.40 \%)$ \\
\hline & Neutral & $43(2.10 \%)$ \\
\hline \multirow{3}{*}{ Restrict travel to endemic area } & Agree & $2052(99.2 \%)$ \\
\hline & Disagree & $10(0.50 \%)$ \\
\hline & Neutral & $7(0.30 \%)$ \\
\hline \multirow{3}{*}{$\begin{array}{l}\text { Inform the higher authorities regarding } \\
\text { suspected case }\end{array}$} & Agree & $1963(94.9 \%)$ \\
\hline & Disagree & $4(0.20 \%)$ \\
\hline & Neutral & $102(4.90 \%)$ \\
\hline \multirow{3}{*}{$\begin{array}{l}\text { Government's plan to control the } \\
\text { pandemic }\end{array}$} & Agree & $1978(95.6 \%)$ \\
\hline & Disagree & $12(0.60 \%)$ \\
\hline & Neutral & $79(3.80 \%)$ \\
\hline
\end{tabular}

participants had sufficient knowledge as reflected by scoring system (score $\geq 6$ ) with statistical significance in relation to age, gender, marital status, occupation and educational level (Table 1). Our study showed that older age and higher educational level had higher scores related to COVID-19 knowledge. Participants who were working in the medical and educational fields had the highest knowledge score while students and military field workers had the lowest scores.

Figure 1 shows the source of COVID-19 information. About $75.9 \%$ of the participants reported that the social media was the main source of their knowledge, followed by newsletters (62.1\%).

\section{Attitude of the Participants related to COVID-19}

The vast majority of the participants agreed and supported the government regulations and the protective measures taken for COVID-19 infection control. Also, 94.9\% of them agreed that higher authorities should be informed in case of suspected cases (Table $\mathbf{3}$ ).

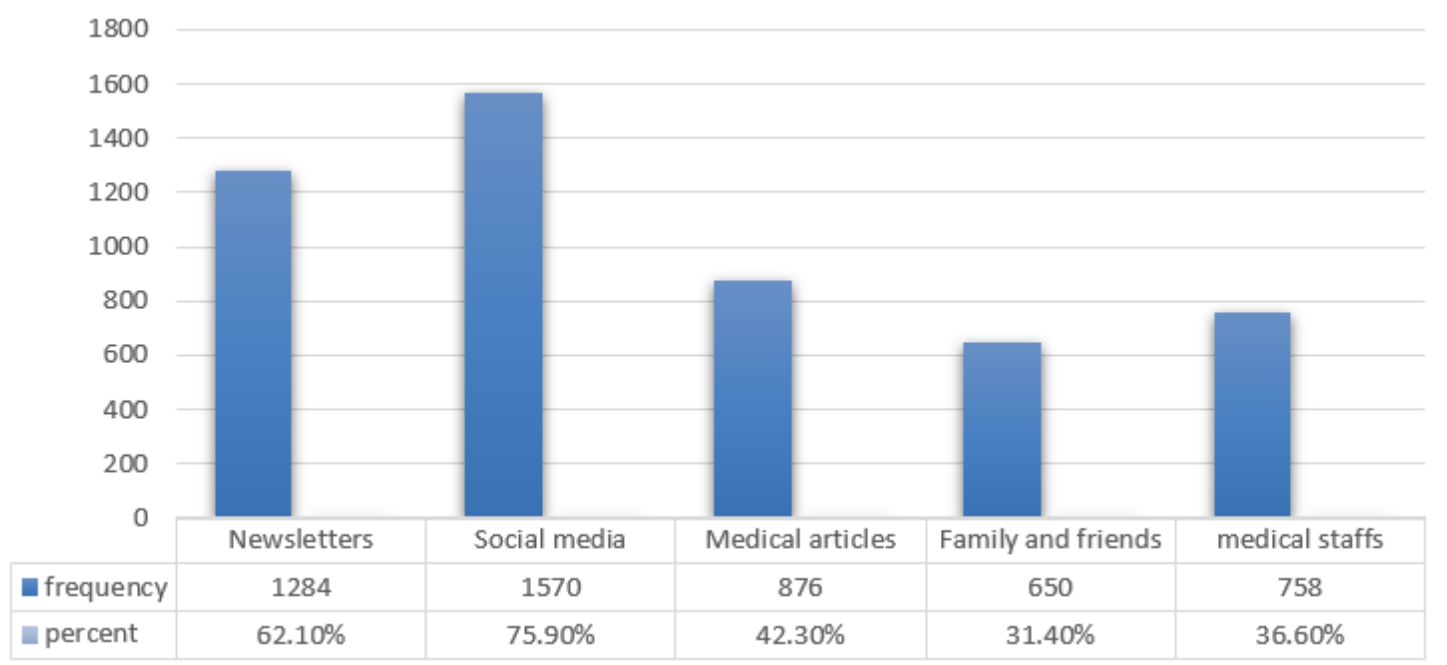

Figure 1. The source of knowledge about COVID-19 among participants 
Table 4. Preventive measures used by the participants against COVID-19 infection

\begin{tabular}{|c|c|c|c|}
\hline Statement & Always & Sometimes & Never \\
\hline Washing hand regularly with soap or with alcohol based hand rub & $1846(89.20 \%)$ & $216(10.40 \%)$ & $7(0.30 \%)$ \\
\hline Maintain at least one meter and half between them and others & $1686(81.50 \%)$ & $356(17.20 \%)$ & $27(01.30 \%)$ \\
\hline Wearing face mask when leaving home & $650(31.40 \%)$ & $693(33.50 \%)$ & $726(35.10 \%)$ \\
\hline Avoid going to crowded area & $1539(74.40 \%)$ & $248(12.00 \%)$ & $282(13.60 \%)$ \\
\hline
\end{tabular}

\section{Practice and Awareness related to Prevention of COVID-} 19

Table 4 shows the different behaviours of the participants related to COVID-19 prevention. The vast majority of the participants reported frequent handwashing $(89.2 \%)$ and maintaining social distancing (81.5\%). Less than one third of the participants reported wearing face mask in public areas (31.4\%).

\section{DISCUSSION}

Several studies have examined the knowledge level, attitude, and practice during previous epidemics such as Swine influenza, Middle East respiratory syndrome coronavirus (MERS-CoV) [10,19-21].

Since the beginning of COVID-19 pandemic, there are several preprints and non-peer reviewed articles that study KAP towards COVID-19 among the public. On the other hand, till the time of writing this manuscript $\left(10^{\text {th }}\right.$ May, 2020), to the best of our knowledge, there are limited published peer-reviewed studies that address KAP toward COVID-19 among the public. One study was conducted in china during the early days of COVID-19 pandemic [11], two studies were conducted in USA [12,13], and one study in Egypt [14].

To the best of our knowledge, this is the first study conducted in Saudi Arabia to examine the KAP related to COVID-19 pandemic among the Saudi population. The questionnaire was distributed widely through various social networks; all over the 13 administrative Saudi regions. Unfortunately, $92.9 \%$ of our participants were from the Eastern Province Region. This may not reflect the status of the whole Saudi population. Yet, it can be explained by the fact that the first confirmed cases of COVID-19 were diagnosed in the Eastern Province.

In our study, we found that the vast majority of our participants had sufficient basic knowledge about COVID19. Most of them were aware about COVID-19 presenting symptoms (96\%), incubation period (92\%), mode of transmission $(88.8 \%)$, high risk groups $(75.9 \%)$, and the unavailability of a vaccine (89.3\%). This could be related to the fact that the majority of our participants had high educational level (university and post graduate) and most of them were working in the medical field. In daily life, social media is the main source of news and information in Saudi Arabia, which shed light on why around $76 \%$ of our participants got most of their knowledge and information from the social media; such as Twitter and WhatsApp. This finding was similar to previous studies related to MERS-CoV that were conducted in Saudi Arabia [10,20]. Abdelhafiz et al reported that the main source of COVID-19 knowledge among the study participants was mainly from social media which is similar to our study, but Facebook was the main social media platform in Egypt [14].

In spite of strict regulations taken by the Saudi Government regarding the prevention of COVID-19 spread, including closing schools, suspending work, and lockdowns, the majority of our participants agreed and supported these recommendations and procedures. Not only that, most of them demonstrated willingness to inform the authorities about any suspected COVID-19 cases.

Although, this survey was conducted only three weeks after the diagnosis of the first case in Qatif City, the vast majority of our participants were aware of the preventive measures and precautions that should be taken to reduce the spread of the infection. More than $80 \%$ of the participants reported frequent handwashing and maintaining social distancing. The vast majority avoided crowded places. These strict practices could be due to the fact that most of our participants had adequate knowledge about COVID-19 and its mode of transmission. To our surprise, less than one third of the participants reported wearing face mask in public areas (31.4\%). During COVID-19 pandemic, recommendation for wearing face masks has been changed. In Chinese study, $98 \%$ of the participants wore face masks when they were outdoors [11], while in the US study [12], only $24 \%$ of their participants wore masks outside their homes. In the Egyptian study, only 35\% confirmed their willingness to wear face mask which is almost similar to our study [14].

At the time of writing our questionnaire, according to $C D C$ recommendation, only health workers must wear face masks at their workplaces. Wearing face masks for the public was not necessary. On April 13, 2020, CDC updated their guidance regarding wearing facial masks. $C D C$ has changed 
its recommendation urging people to wear cloth face coverings in crowded public places with significant infection transmission [22], since most of COVID-19 patients are asymptomatic or have mild symptoms.

\section{Strengths and Limitations}

Recruiting large sample of participants during this critical period is considered to be strength to our study. On the other hand, our study had some limitations: First, the study lacks generalizability to Saudi population as most of our participants were from the Eastern Province. Second, because data related to COVID-19 are evolving, answers to knowledge related questions were not validated, especially the therapeutic intervention questions. For instance, antimalarial drugs (hydroxychloroquine) was used in the management of COVID-19 at the beginning of the pandemic but recent studies showed conflicting data regarding its effectiveness [23].

\section{CONCLUSION}

Although our study was conducted at the beginning of COVID-19 pandemic in Saudi Arabia, it showed that our participants had good knowledge, which was reflected on their positive attitude, awareness, and their precautionary measures. Because our participants were mainly from the Eastern province, further studies are needed to investigate KAP related to COVID-19 in other regions of Saudi Arabia.

\section{ACKNOWLEDGEMENT}

The authors would like to thank Dr Ghadah Alqudaihi, Epidemiologists in $\mathrm{QCH}$.

\section{DECLARATION OF CONFLICT OF INTEREST}

The authors received no financial support for the research and/or authorship of this article. There is no conflict of interest.

\section{REFERENCES}

1. Zhu N, Zhang D, Wang W, Li X, Yang B, Song J, Zhao X, Huang $B$, Shi W, Lu R, Niu P. A novel coronavirus from patients with pneumonia in China, 2019. New England Journal of Medicine. 2020 Jan 24. (doi: 10.1056/NEJMoa2001017).

2. Person. COVID-19 situation update worldwide, as of 10 May 2020 [internet]. European Centre for Disease Prevention and Control. ECDC; 2020. Available at: https://www.ecdc.europa.eu/en/geographicaldistribution-2019-ncov-cases
3. The Ministry of Health $(\mathrm{MOH})$. [Internet]. $\mathrm{MOH}$ News $\mathrm{MOH}$ Reports First Case of Coronavirus Infection. Available at: https://www.moh.gov.sa/en/Ministry/ MediaCenter/News/Pages/News-2020-03-02-002.aspx

4. Person. Confirmed COVID-19 cases exceed 39,000 in Saudi Arabia [Internet]. Arab News. Arabnews; 2020. Available at: https://www.arabnews.com/node/1672706 /saudi-arabia

5. China coronavirus: Lockdown measures rise across Hubei province [Internet]. BBC News. BBC; 2020. Available at: https://www.bbc.com/news/world-asia-china-51217455

6. Elbahrawy Farah, Al Othman Reema. Saudi Arabia Puts City in Eastern Province Under Virus Lockdown. Bloomberg. 2020 March 8. Available at: https://www.bloomberg.com/news/articles/2020-0308/saudi-arabia-puts-city-in-eastern-province-undervirus-lockdown

7. Person. Saudi Arabia closes schools over coronavirus concerns [Internet]. Arab News. Arabnews; 2020. Available at: https://www.arabnews.com/node/ 1638606/saudi-arabia (Accessed: April 16, 2020).

8. Person. Kingdom's government decides to suspend attendance at workplaces in all government agencies for period of (16) days except for health, security, military and electronic security center. [internet]. Saudi Press Agency. Saudi Press Agency; 2020. Available at: https://www.spa.gov.sa/viewfullstory.php?lang=en\&ne wsid=2047989 (Accessed: April 16, 2020).

9. Almutairi KM, Al Helih EM, Moussa M, Boshaiqah AE, et al. Awareness, attitudes, and practices related to coronavirus pandemic among public in Saudi Arabia. Family \& community health. 2015 Oct 1;38(4):332-40. (doi: 10.1097/FCH.0000000000000082).

10. Al-Hazmi A, Gosadi I, Somily A, Alsubaie S, Saeed AB. Knowledge, attitude and practice of secondary schools and university students toward Middle East Respiratory Syndrome epidemic in Saudi Arabia: A cross-sectional study. Saudi journal of biological sciences. $2018 \mathrm{Mar}$ 1;25(3):572-7. (doi: 10.1016/j.sjbs.2016.01.032).

11. Zhong BL, Luo W, Li HM, Zhang QQ, et al. Knowledge, attitudes, and practices towards COVID-19 among Chinese residents during the rapid rise period of the COVID-19 outbreak: a quick online cross-sectional survey. International journal of biological sciences. 2020;16(10):1745. (doi: 10.7150/ijbs.45221). 
12. Clements JM. Knowledge and Behaviors toward COVID19 among US Residents during the Early Days of the Pandemic: Online Questionnaire. JMIR public health and surveillance. 2020 May 5. (doi: 10.2196/19161).

13. Wolf MS, Serper M, Opsasnick L, O'Conor RM, et al. Awareness, attitudes, and actions related to COVID-19 among adults with chronic conditions at the onset of the US outbreak: A cross-sectional survey. Annals of Internal Medicine. 2020 Apr 9. (doi: 10.7326/M20-1239).

14. Abdelhafiz AS, Mohammed Z, Ibrahim ME, Ziady HH, et al. Knowledge, perceptions, and attitude of Egyptians towards the novel coronavirus disease (COVID-19). Journal of Community Health. 2020 Apr 21:1-0. (doi: 10.1007/s10900-020-00827-7).

15. Nemati M, Ebrahimi B, Nemati F. Assessment of Iranian nurses' knowledge and anxiety toward COVID-19 during the current outbreak in Iran. Archives of Clinical Infectious Diseases. 2020;15(COVID-19). (doi: 10.5812/archcid.102848).

16. Peng Y, Pei C, Zheng Y, Wang J, et al. Knowledge, attitude and practice associated with COVID-19 among university students: a cross-sectional survey in China. (doi: 10.21203/rs.3.rs-21185/v1).

17. Naser AY, Dahmash EZ, Alwafi H, Alsairafi ZK, et al. Knowledge and practices towards COVID-19 during its outbreak: a multinational cross-sectional study. medRxiv. 2020 Jan 1. (doi: 10.1101/2020.04.13.20063560).
18. General authority for statistics, kingdom of Saudi Arabia [internet]. Population by Age Groups and Gender 2019. Available at: https://www.stats.gov.sa/en/43

19. Balkhy $\mathrm{HH}$, Abolfotouh MA, Al-Hathlool RH, Al-Jumah MA. Awareness, attitudes, and practices related to the swine influenza pandemic among the Saudi public. BMC infectious diseases. 2010 Dec 1;10(1):42. (doi: 10.1186/1471-2334-10-42).

20. Asaad AM, El-Sokkary RH, Aedh Al, Ali Alzamanan MA, Khalil FO. Exploring Knowledge and Attitude toward Middle East Respiratory Syndrome-Coronavirus (MERSCoV) Among University Health Colleges' Students, Saudi Arabia: A Cross-Sectional Study. American Journal of Infectious Diseases [Internet]. Science Publications; 2019 Jan 1;15(1):37-43. (doi: 10.3844/ajidsp.2019.37.43).

21. Alsahafi AJ, Cheng AC. Knowledge, attitudes and behaviours of healthcare workers in the Kingdom of Saudi Arabia to MERS coronavirus and other emerging infectious diseases. International journal of environmental research and public health. 2016 Dec;13(12):1214. (doi: 10.3390/ijerph13121214).

22. Person. Recommendation regarding the use of cloth face coverings, especially in areas of significant communitybased transmission [Internet]. CDC. CDC; 2020. Available at: https://www.cdc.gov/coronavirus/2019-ncov/hcp/ using-ppe.html

23. Magagnoli J, Narendran S, Pereira F, Cummings T, et al. Outcomes of hydroxychloroquine usage in United States veterans hospitalized with Covid-19. medrxiv. Apr 1. (doi: 10.1101/2020.04.16.20065920). 